\title{
Chilling Effect of Inoculation on the Microstructure and Hardness Property of Hypo-Eutectic Grey Cast Iron
}

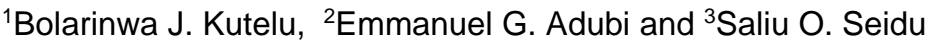 \\ ${ }^{1}$ Department of Mineral and Petroleum Resources Engineering Technology, Federal Polytechnic, Ado Ekiti, Nigeria \\ ${ }^{2}$ Department of Mechanical Engineering, Federal Polytechnic, Ado Ekiti, Nigeria \\ ${ }^{3}$ Department of Metallurgical and Materials Engineering, Federal University of Technology, Akure, Nigeria \\ rinwa@yahoo.com / obafemiadubi@gmail.com I seidu2@yahoo.co.uk
}

Received: 10-FEB-2021; Reviewed: 21-MAR-2021; Accepted: 25-APR-2021

http://dx.doi.org/10.46792/fuoyejet.v6i2.614

\begin{abstract}
The influence of varied weight percent of inoculant (ferrosilicon) on the microstructure and hardness property of hypo- eutectic grey cast iron was investigated. Four sets of chill wedge samples were produced using two chill wedge wooden patterns $\left(W_{3.5}\right.$ and $\left.W_{4}\right)$. The first set, the control samples $W_{3.5}$ and $W_{4}$ were uninoculated. The second, third and fourth sets were inoculated with $1.0 \mathrm{wt} . \%, 1.5 \mathrm{wt} . \%$ and $2 w t . \%$ ferrosilicon respectively to give inoculated samples $W_{3.5}$ and $W_{4}$. Wedge test was conducted on the samples at the four different points $(1,2,3$ and 4) in accordance with ASTM A367. From the results, microstructures of the control and the inoculated samples were differently influenced by the varied percentage of the inoculant at the four designated points 1, 2, 3 and 4 . The average hardness property of the inoculated samples decreases with increasing ferrosilicon addition. Samples $W_{3.5}$ and $W_{4}$ with 1.0 wt. \% ferrosilicon revealed high hardness property at chill zone, and hardness property of $W_{3.5}$ was high relative to sample $W_{4}$ with the values of 34.9 HRA and 30.6 HRA respectively. Similarly, the control samples showed the highest hardness property at the chill zone. Sample $W_{3.5}$ revealed high hardness value of 33.0 HRA relative to sample $\mathrm{W}_{4}$ of $26.8 \mathrm{HRA}$ at the chill zone.
\end{abstract}

Keywords- inoculant, Microstructure, hypo- eutectic, chill zone, hardness property

\section{INTRODUCTION}

rey cast iron is the most common type of all cast irons

Jith carbon content between 3-3.5\%. Grey cast iron is used in a wide range of application. It has been suitably used in automotive industry for vital engine components such as engine block and brake (Riposan et al., 2009; Seidu, 2009), pump impellers, base or beds of machineries (Sherrif et al., 2019). The unique combination of reasonable strength, good corrosion resistance, high thermal conductivity, good wear resistance, excellent heat conductivity, high machinability, vibration damping capacity and good castability afford the material wide range of industrial applications (Saliu et al., 2020; Riposan et al., 2009; Edalati et al., 2004). Inoculation is a viable route of controlling the solidification process, and hence, the structure and properties of cast iron. It minimizes undercooling and increase the number of nucleation sites during solidification.

In addition, it prevents undercooling of casting to temperatures below the metastable eutectic where carbidic structures are formed (Edward, et al., 2015). The iron solidification mechanism is prone to form chilled iron structures when inoculation is inadequate, and chilling tendency is one of the viable approaches of evaluating the effect of inoculation on cast iron (Diego et al., 2015; Darrell, 1964). Research findings have shown that excessive fines in inoculant lead to poor result, because they are already oxidized and over inoculation leads to increase in shrinkage tendency of metal (Maschke, 2013).

*Corresponding Author

Section C- MECHANICAL ENGINEERING \& RELATED PHYSICAL SCIENCES Can be cited as:

Kutelu B.J., Adubi E.G. and Sedu S.O. (2021): Chilling Effect of Inoculation on the Microstructure and Hardness Property of Hypo-Eutectic Grey Cast Iron, FUOYE Journal of Engineering and Technology (FUOYEJET), 6(2), 72-77. http://dx.doi.org/10.46792/fuoyejet.v6i2.614
Therefore, in this study, attempt was made to produce homogeneous and fine microstructure in grey cast through proper mixing of ferrosilicon into the metal. Consequently, varied percentage of the inoculant was used. This is with the aim of evaluating its chilling effect on the microstructure and hardness properties of grey cast iron.

\section{Methodology \\ 2.1 MATERIALS}

The materials used are scrap (auto parts), graphite, limestone- fluxing agent (Sherrif et al., 2019) and ferrosilicon, FeSi (78\% Si, $0.21 \% \mathrm{Al}$, Fe-bal). Shown in Table 1 is the elemental composition of the scrap.

Table 1. Elemental composition of the scrap

\begin{tabular}{cccc}
\hline Element & \% Comp. & Element & \% Comp. \\
\hline $\mathrm{C}$ & 3.97 & $\mathrm{Nb}$ & $<0.0025$ \\
$\mathrm{Si}$ & 1.94 & $\mathrm{~V}$ & 0.0099 \\
$\mathrm{Mn}$ & 0.87 & $\mathrm{~W}$ & $<0.010$ \\
$\mathrm{P}$ & 0.088 & $\mathrm{~Pb}$ & 0.0083 \\
$\mathrm{~S}$ & 0.131 & $\mathrm{~B}$ & $<0.0005$ \\
$\mathrm{Cr}$ & 0.163 & $\mathrm{Sn}$ & 0.0083 \\
$\mathrm{Ni}$ & 0.58 & $\mathrm{Zn}$ & 0.0081 \\
$\mathrm{Mo}$ & 0.0015 & $\mathrm{Bi}$ & $<0.0015$ \\
$\mathrm{Al}$ & 0.0058 & $\mathrm{Ce}$ & $<0.0030$ \\
$\mathrm{Cu}$ & 0.137 & $\mathrm{Zr}$ & $<0.0015$ \\
$\mathrm{Co}$ & 0.015 & $\mathrm{La}$ & $<0.0033$ \\
$\mathrm{Ti}$ & 0.0015 & $\mathrm{Fe}$ & 92.5 \\
\hline
\end{tabular}

\subsection{MethOdS}

Silica sand, bentonite, coal dust and water were used to produce standard sand moulds. The sand moulds were prepared in accordance with ASTME2349-19. Grey cast 
iron scraps and graphite were charged into the rotary, and temperature of the furnace was monitored at regular interval using molten metal pyrometer Model MFP-200, manufactured by Atech Instrument and Controls. The molten metal was tapped into a $60 \mathrm{~kg}$ ladle at $1485{ }^{\circ} \mathrm{C}$. The Fe-Si alloy inoculant (78\% Si, $0.21 \% \mathrm{Al}$, Fe-bal) was added directly in the stream while pouring the melt into the ladle to ensure proper mixing. The first melt tapped was uninoculated (control). The second, third, fourth and fifth melts were inoculated with $1.0 \mathrm{wt} \%, 1.5 \mathrm{wt} \%$ and $2 w t \%$ ferrosilicon respectively. Standard chill wedges of $W_{3.5}$ and $W_{4}$, specified in the ASTM Standard A367-60 wedge test were used for the experiment. Chemical compositions of the control and inoculated samples were obtained by Optical Emission Spectroscopy testing machine (ARL QuantoDesk Spectro Analysis Machine), and the result is presented in Table 2.

\subsubsection{Chill Measurement}

The wedge samples were strickened with hammer and fractured as shown in Figure 1. From Figure 2, the portion nearest the apex entirely free of any grey spots is designated as the clear chill $\left(\mathrm{W}_{\mathrm{c}}\right)$. That portion starting with the end of the clear chill and continuing to the location where the last spot of cementite or white iron is visible is designated as the mottled zone $\left(\mathrm{W}_{\mathrm{m}}\right)$. Whereas the portion of the wedge measured from the junction of the gray fracture with the first appearance of chilled iron to the apex is designated as the total chill $\left(\mathrm{W}_{\mathrm{t}}\right)$. The parameters relative clear chill (RCC), relative average mottled chill (RMC) AND relative total chill (RTC) (Riposan et al., 2009) were also considered:

$$
\begin{aligned}
& \mathrm{RCC}=100(\mathrm{Wc} / \mathrm{B}) \% \\
& \mathrm{RMC}=100(\mathrm{Wm} / \mathrm{B}) \% \\
& \mathrm{RCC}=100(0.5(\mathrm{Wc}+\mathrm{Wm}) / \mathrm{B}) \%
\end{aligned}
$$

where $\mathrm{B}$ is the maximum width of the test wedge as shown in Table 2.

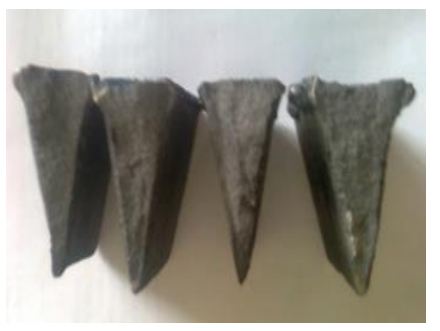

Fig.1: Fractured wedge surface

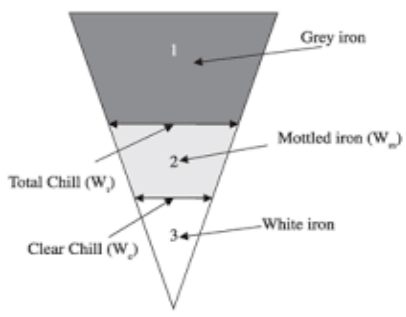

Fig. 2: Cross-section of the chill wedge at the three sections

\subsubsection{Microstructure}

The metallographic samples were prepared in accordance with ASTM A367-11(2017), using the fractured wedge test samples. One halves of the samples (Figure 1) were prepared for metallographic observations, using emery papers of sizes 60, 120, 240, 320, 400, 800 and 1200 microns in succession. The ground samples were mechanically polished using a polishing cloth and a 0.3 micron $\mathrm{SiC}$ polishing powder (Kay and Struers, 2006). After which, they were etched in nital solution (3\% nitric acid and 97\% ethanol) for 3-4 min and cleaned with alcohol for microscopic examination. Optical metallurgical microscope Olympus Model GX51, manufactured by Leco Corporation was used at $x$ 200. The samples were viewed at the four designated points in Figure 3. Points 1 is the chill zone, point 2 is the mottle zone, and points 3 and 4 are the grey zone (Riposan et al, 2009). The analysis was carried out in accordance with ASTM A247-19.

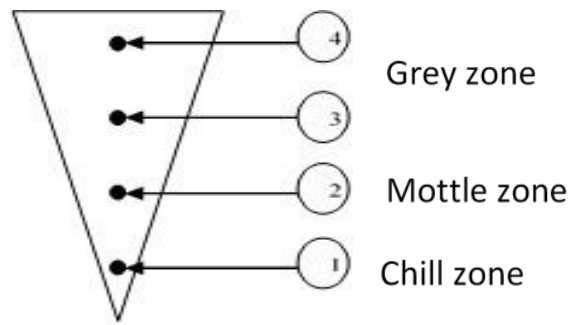

Fig. 3: Cross-section of the chill wedge at the four points

\subsubsection{Hardness Testing}

The fractured chill wedge samples were used to prepare standard hardness samples. Similarly, test was conducted at four points on each of the wedge sample (Figure 3). Digital Rockwell Hardness Tester Model, manufactured by Tinius Olsen was employed. A maximum load of $60 \mathrm{kgf}$ was applied with residence time of 10 seconds. Three indentations were made with gap of about $3 \mathrm{~mm}$ in-between (Oyetunji et al., 2013). The average values, which were measured on scale A were determined and recorded as shown in Table 2.

\section{RESULTS AND DISCUSSION 3.1 Chemical ANALYSIS}

The chemical analysis of the experimental samples are shown in Table 2. From the results, carbon equivalent (CE) of the control iron is $3.15 \%$, while CE of the inoculated iron is in the range of $3.08-3.17 \%$, making the samples hypoeutectic irons. No significant difference exist between carbon, manganese, sulphur and phosphorus contents of the control and inoculated samples. However, the observed increased silicon contents of the inoculated samples relative to the control sample could be hinged on the inoculation effect (Maschke, 2013). 
Table 2. Chemical Compositions of the Experimental Grey Cast Irons

\begin{tabular}{llllllllll}
\hline $\begin{array}{l}\text { Sample } \\
\text { Description }\end{array}$ & $\mathbf{6}$ & $\mathbf{S i}$ & $\mathbf{M n}$ & $\mathbf{P}$ & $\mathbf{S}$ & $\mathbf{A l}$ & $\mathbf{( w t . \% )}$ & & (S) \\
\hline U.I. & 3.08 & 2.45 & 0.234 & 0.088 & 0.135 & 0.0010 & 3.15 & 1.73 & 0.032 \\
1.0 wt.\% alloy & 3.01 & 2.93 & 0.220 & 0.069 & 0.143 & 0.0076 & 3.08 & 1.54 & 0.031 \\
1.5 wt.\% alloy & 3.10 & 2.98 & 0.201 & 0.060 & 0.140 & 0.0087 & 3.17 & 1.43 & 0.028 \\
2.0 wt.\% alloy & 3.03 & 2.98 & 0.101 & 0.071 & 0.149 & 0.0098 & 3.10 & 0.68 & 0.015
\end{tabular}

Table 3. Microstructures of the uninoculated (control) wedge test samples $W_{3.5}$ and $W_{4}$ at the four Points, and $\times 200$

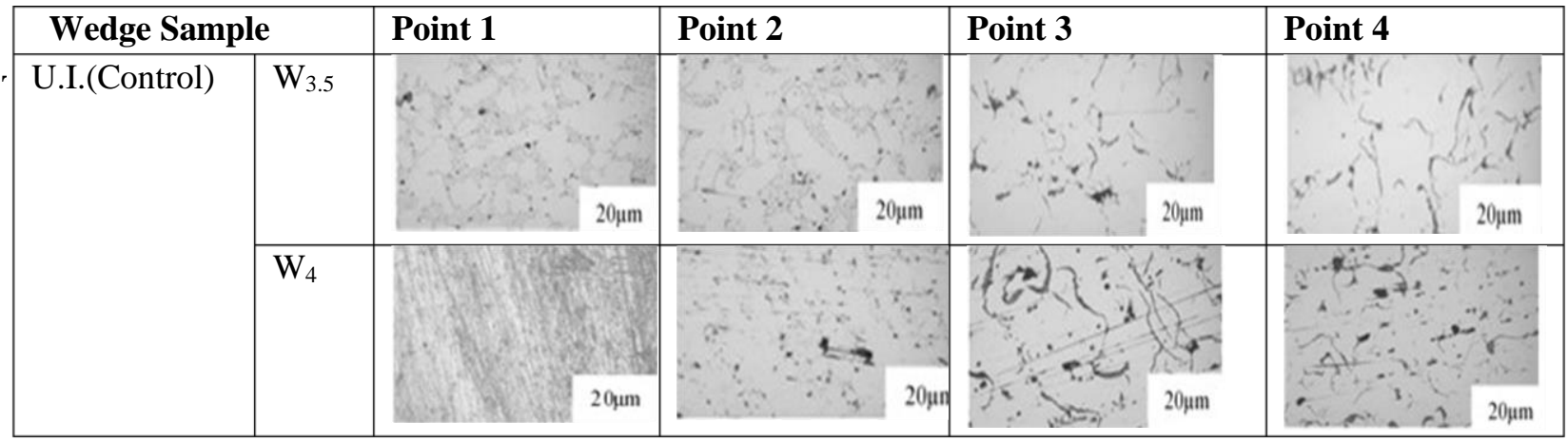

\subsection{Optical Microstructure of the Control SAMPLE}

Table 3 shows microstructures of the control wedge samples $W_{3.5}$ and $W_{4}$ at points 1,2,3 and 4 . The chill zone consists of thin and long Type D interdendritic flake graphite in ferrite matrix, accompanied in between by graphite inclusions and surrounded by cementite phase. Cementite phase resulted due to rapid cooling of the zone, during which, there was no enough time for carbon to precipite as graphite (Saliu et al., 2020; Sheriff et al., 2019; Shashikantha et al., 2017). Microstructure of the mottle zone is comprised of Type D interdendritic flake graphite in ferrite matrix. However, the flakes are somewhat thinner and shorter. The grey zone reveals the presence of Type D graphite, which is accompanied by Type $\mathrm{E}$ in ferrite matrix. Points 3 and 4 whose morphologies are not exactly the same can be attributed to the slight difference in cooling gradient. The variations that exist in microstructures of the samples $\mathrm{W}_{3.5}$ and $\mathrm{W}_{4}$, and at the various zones were due section size. This is because structure of zone is primarily a function of cooling rate. In turn, cooling rate is primarily a function of section size (Harold et al., 2017; Riposan et al., 2009; Darrell, 1964) .

\subsection{Optical Microstructure of the InOculated WEDGe SAMPLES}

Table 4,5 and 6 are microstructures of $1.0 \%, 1.5 \%$ and $2.0 \%$ FeSi inoculated wedge samples $W_{3.5}$ and $W_{4}$ respectively. Microstructures of the chill zone sample $\mathrm{W}_{3.5}$ and $\mathrm{W}_{4}$ with $1.0 \%$ FeSi (Table 4 ) consist of very thin and close network of interdendritic flake graphite (Type E graphite), surrounded by cementite phase in pearlitic matrix with graphite inclusions. Also, the chill zone sample $\mathrm{W}_{4}$ reveals few areas of Type D graphite flakes. The relative high degree of undercooling with attendant few number of nucleation sites during solidification of melt accounted for the microstructural characteristics (Edward et al., 2015; Soiński and Wawrzyniec, 2010).

The mottled zone sample $W_{3.5}$ consists of dispersed Type-A graphite flakes in pearlitic matrix with graphite flake inclusions, and the mottled zone sample $\mathrm{W}_{4}$ is characterized by Type-A graphite flakes and a few Type$\mathrm{D}$ graphite flakes in pearlitic matrix with more graphite flake inclusions. These structures resulted from the moderate cooling rates that characterised the zone (Maschke, 2013), and the presence of more graphite inclusion in sample $W_{4}$ could be attributed to the relative frapid cooling rate that resulted from smaller section size (Saliu et al., 2020; Maschke, 2013).

The grey zone samples $W_{3.5}$ and $W_{4}$ microstructures at point 3 reveal the presence of very fine TYPE-A graphite flakes, which are randomly oriented and uniformly distributed with few areas of TYPE-D interdendritic graphite in a pearlitic matrix. However, sample $W_{3.5}$ microstructure shows a more randomly oriented and uniformly distributed graphite flakes with few areas of TYPE-D interdendritic graphite as compared to sample $\mathrm{W}_{4}$. The variations were due to differences in section size, and hence, cooling rates o samples. 
Table 4. Microstructures of 1.0wt.\% FeSi inoculated wedge test samples $W_{3.5}$ and $W_{4}$ at the four Points, and $x 200$

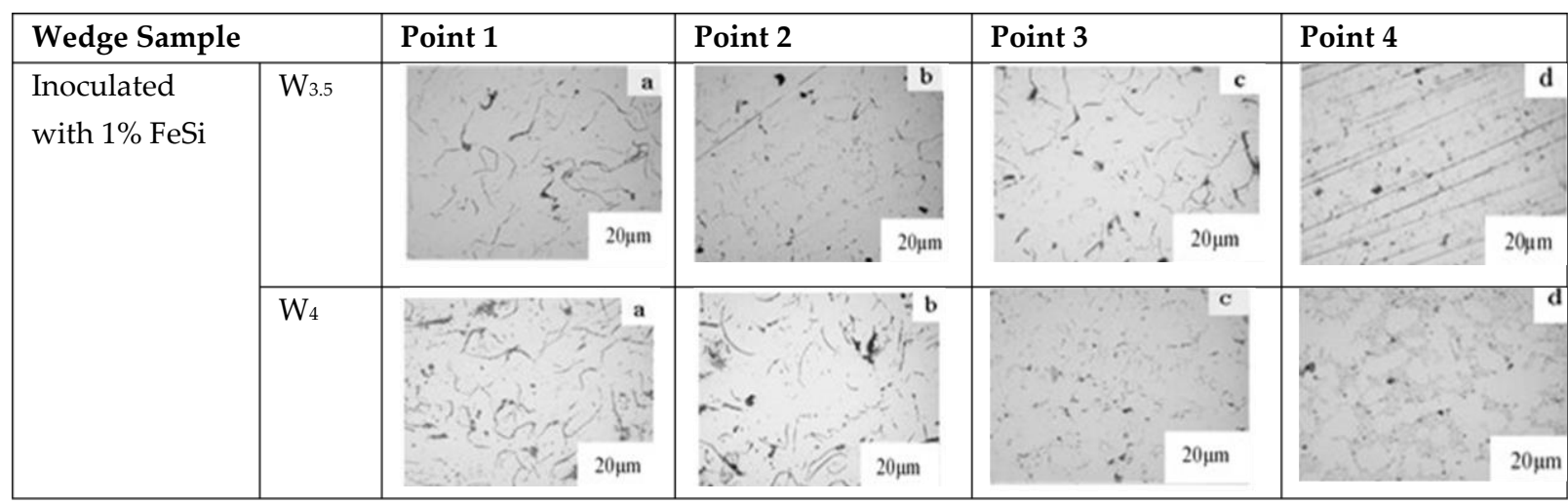

Table 5. Microstructures of $1.5 \mathrm{wt}$ \% FeSi inoculated wedge test samples $W_{3.5}$ and $W_{4}$ at the four Points, and $x 200$

\begin{tabular}{|c|c|c|c|c|c|}
\hline \multicolumn{2}{|l|}{ Wedge Sample } & Point 1 & Point 2 & Point 3 & Point 4 \\
\hline $\begin{array}{l}\text { Inoculated } \\
\text { with } 1 \quad \text { wt. } \% \\
\text { FeSi }\end{array}$ & $\mathrm{W}_{3.5}$ & $\therefore \quad a$ & $\because x^{b}$ & 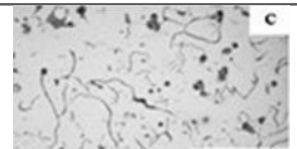 & 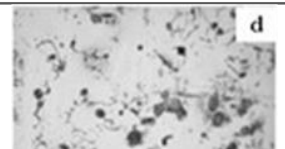 \\
\hline & $\mathrm{W}_{4}$ & 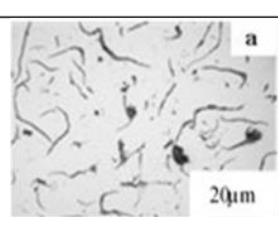 & $\int_{1}^{x} \leq 20 \mu \mathrm{m}$ & $\therefore \quad i=\frac{1}{20 \mu \mathrm{m}}$ & 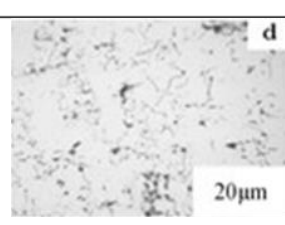 \\
\hline
\end{tabular}

Table 6. Microstructures of 2.0wt.\% FeSi inoculated wedge test samples $W_{3.5}$ and $W_{4}$ at the four Points, and $x 200$

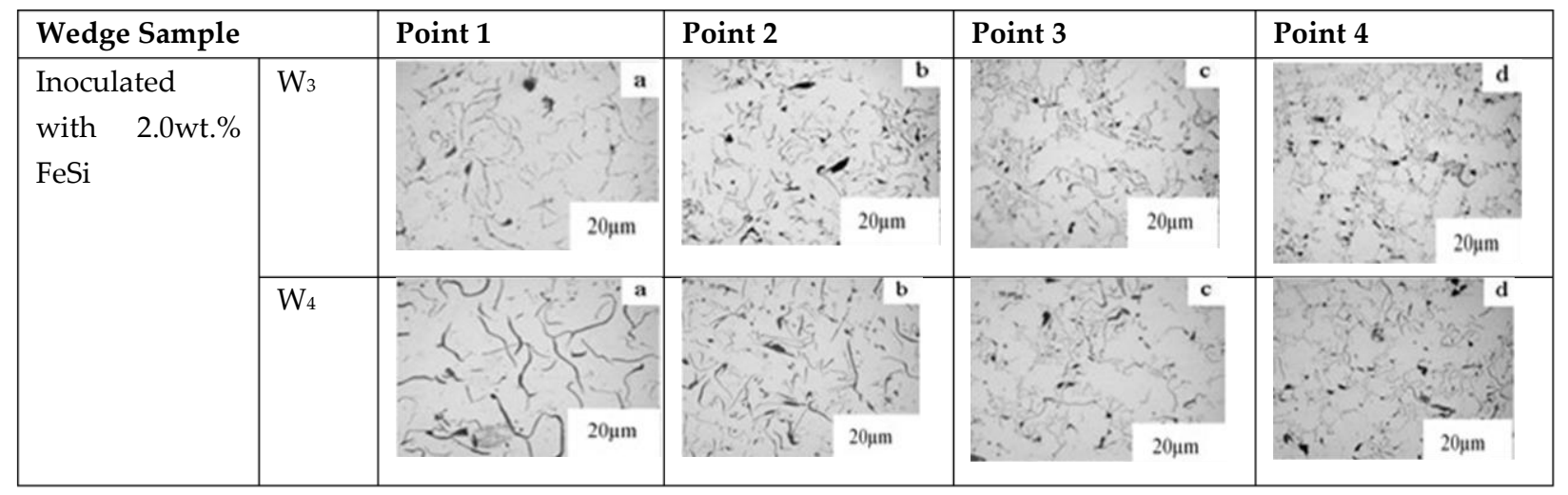

Microstructures of the grey zone sample $\mathrm{W}_{3.5}$ (point 3) show rather coarse, shorter and wider randomly oriented graphite flakes relative to the grey zone sample $\mathrm{W}_{4}$, which was due to accompanied relative small degree of undercooling. Hence, production of smaller cell size nuclei during melt solidification. The drastic reduction of chill depth of the iron at this zone was due to presence of the smaller cell size nuclei during the characteristic slow cooling rate of the zone (Shashikantha et al., 2017; Maschke, 2013; Edalati et al., 2004).

Microstructures of chill zone samples $\mathrm{W}_{3.5}$ and $\mathrm{W}_{4}$ with $1.5 \%$ FeSi (Table 5) reveal long and thin Type A graphite flakes and a few areas of thin and uniformly oriented Type D graphite flakes matrix in pearlitic, accompanied by cementite phase. Formation of Type A graphite flakes was influenced by the inoculation (Saliu et al., 2020; Sheriff et al., 2019; Darrell, 1964), while the Type D flakes and cementite phase resulted from high rate of cooling. Accordingly, Type D graphite flake is found in hypoeutetic or eutectic iron at rather high cooling rates (Maschke, 2013). The relative increased presence of Type D flakes and cementite phase in microstructures of chill zone samples $\mathrm{W}_{4}$ is attributable to higher cooling rates that resulted from reduced section size. Also, the increased cementite phase of sample $\mathrm{W}_{4}$ as compared to 
$W_{3.5}$ can be explained by the increased cooling rates that was due to reduced section size (Fraś et al., 2014) Microstructures of the mottle zone samples $W_{3.5}$ and $W_{4}$ are characterized by Type A graphite flakes. These flakes are short, fairly distributed and uniformly oriented in pearlitic matrix relative to the chill zone samples. Graphite flakes in sample $\mathrm{W}_{4}$ are somewhat thinner and less uniformly oriented due higher degree of undercooling during the melt solidification. Microstructures of the grey zone samples $W_{3.5}$ and $W_{4}$ at point 3 consist of uniformly distributed Type A graphite flakes in pearlitic matrix. The flakes are somewhat thick as compared to those of the corresponding mottle zone. The slight changes in microstructures of the sample at point 4 were due to the resulting higher degree of undercooling (Shashikantha et al., 2017; Fraś et al., 2014; Maschke, 2013).

Microstructures of chill zone samples $W_{3.5}$ and $W_{4}$ with 2.0wt.\% FeSi (Table 6) show very fine Type B graphite (rosette structure) and small areas of Type A graphite flakes in pearlitic matrix, accompanied by cementite phase. The Type B graphite flake resulted from high silicon of the inoculant (Haji, 2014; Maschke, 2013; Soiński et al., 2010), and the cementite phase was due to undercooling that was a result of insufficient heat liberated by the few cell growing to arrest the temperature (Edward al., 2015; Maschke, 2013), and the increased presence of cementite phase in sample $\mathrm{W}_{4}$ relative to $W_{3.5}$ was due to increased undercooling that resulted from small section size. Microstructures of the mottle zone samples $W_{3.5}$ and $W_{4}$ are characterized by Type B graphite (rosette structure) and larger areas of Type A graphite flakes in pearlitic matrix. The larger areas of Type A graphite flakes was due to less rapid cooling, during which, undercooling was at a moderate degree. The obvious little difference in the microstrucures of grey zone samples $W_{3.5}$ and $W_{4}$, which consist of Type B graphite flake with a relative perfect randomly oriented and uniformly distributed Type-A graphite in pearlitic matrix was due to slow rate of cooling rate that is associated with the zone (Shashikantha et al., 2017; Maschke, 2013).

\subsection{HARDNESS}

The control wedge samples and the inoculated wedge samples $W_{3.5}$ and $W_{4}$ reveal highest hardness values at the chill zone (Table 6), which was attributed to the resulting increased presence of cementite phase from fast cooling rate (Seidu, 2009; Stan et al., 2009). Also, the increased hardness of wedge samples $W_{3.5}$ relative to the wedge sample $W_{4}$ was accounted for by the fast cooling rate from the relative reduced section size (Maschke, 2013; Riposan et al., 2009).

The low hardness values of the inoculated wedge samples relative to the control wedge samples was due to graphatisation effect of inoculation. The inoculant minimized undercooling to temperatures below the metastable eutectic where carbidic structures are formed and at the same time increased the number of nucleation sites during solidification (Borse and Mangulkar, 2014), and in The decrease in hardness values of the inoculated samples with increasing inoculant addition was due to increased cementite instability that resulted from increased presence of silicon (Saliu et al., 2020: ). The wedge samples $W_{3.5}$ revealed high hardness values relative to wedge sample $W_{4}$ due to the higher cooling rate of the former. It is well known that when the rate of cooling is inreased, both graphite size and matrix structure are refined, and in consequence, strength and hardness are increased (Sheriff et al., 2019).

\section{CoNCLUSION}

The following conclusions were drawn from the study:

1. Microstructures of the control wedge samples $W_{3.5}$ and $W_{4}$ were consisted majorly of varying sizes of Type $D$ interdendritic flakes graphite in ferrite matrix with cementite phase at the chill, mottle and grey zones.

2. Morphology (Types of graphite flake and size) of the inoculated wedge samples $W_{3.5}$ and $W_{4}$ at the chill, mottle and grey zones were modified (improved) at varying degree with the varied percentage of inoculant addition, particularly under moderate and slow cooling conditions. 3. The presence of Type A graphite flakes and Type B graphite (rosette structure) were more with $1.0 \mathrm{wt} . \%$ and $2.0 \mathrm{w} t \% \mathrm{FeSi}$ additions respectively.

4. Hardness values of the inoculated samples $W_{31 / 2}$ and $\mathrm{W}_{4}$ were decreased as the inoculant addition was increased, and the highest hardness values were obtained with $1.0 \mathrm{wt}$. $\%$ addition.

5. For the control and inoculated samples, hardness property of $W_{3.5}$ was high relative to sample $W_{4}$, and the chill zone revealed the highest hardness.

6. The respective optimum average hardness values of the wedge sample $W_{3.5}$ for the control and inoculated samples are 33.0 HRA and 29.3 HRA and for the wedge sample $\mathrm{W}_{4}$, the corresponding values are $22.6 \mathrm{HRA}$ and $22.2 \mathrm{HRA}$.

Table 7: Hardness values of chill wedge samples

\begin{tabular}{|c|c|c|c|c|c|c|}
\hline $\begin{array}{l}\text { Samples' } \\
\text { Wedge } \\
\text { Number }\end{array}$ & $\begin{array}{c}\text { Sample } \\
\text { Description } \\
\text { (Grey cast iron) }\end{array}$ & $\begin{array}{l}\text { Point } 1 \\
\text { Hardness } \\
\text { Value }\end{array}$ & $\begin{array}{c}\text { Point } 2 \\
\text { Hardness } \\
\text { Value }\end{array}$ & $\begin{array}{c}\text { Point } 3 \\
\text { Hardness } \\
\text { Value }\end{array}$ & $\begin{array}{c}\text { Point } 4 \\
\text { Hardness } \\
\text { Value }\end{array}$ & $\begin{array}{c}\text { Average Hardness } \\
\text { Value }\end{array}$ \\
\hline \multirow{4}{*}{$W_{3.5}$} & Control. & 38.3 & 34.4 & 30.7 & 28.5 & 33.0 \\
\hline & $1.0 \mathrm{wt} . \%$ inoc. & 34.9 & 31.0 & 29.2 & 21.9 & 29.3 \\
\hline & $1.5 \mathrm{wt} . \%$ inoc. & 33.1 & 26.8 & 21.8 & 19.7 & 26.4 \\
\hline & $2.0 \mathrm{wt} . \%$ inoc. & 28.5 & 28.1 & 24.2 & 15.3 & 24.0 \\
\hline \multirow{4}{*}{$\mathrm{W}_{4}$} & Control. & 32.3 & 30.5 & 23.3 & 22.6 & 26.8 \\
\hline & $1.0 \mathrm{wt} . \%$ inoc. & 30.6 & 27.1 & 25.3 & 22.2 & 26.3 \\
\hline & 1.5 wt. $\%$ inoc. & 24.6 & 24.4 & 21.2 & 18.7 & 22.7 \\
\hline & 2.0 wt. $\%$ inoc. & 22.9 & 20.3 & 17.7 & 17.4 & 19.6 \\
\hline
\end{tabular}




\section{REFERENCES}

American Society for Testing of Material (2017), ASTM A367-11, Standard Test Methods of chill testing of cast iron, ASTM International, West Conshohocken, PA

American Society for Testing of Material (2019), ASTM E2349-19, standard practice for safety requirements in metal casting operations: sand preparation, molding, and core making; melting and pouring, and cleaning and finishing, ASTM International, West Conshohocken, PA

Borse, S.C. and Mangulkar, Y.E. (2014). Review on grey cast iron inoculation, International Journal of Innovative Research in Science, Engineering and Technology, 3(4), 30-36

Darrell W. D. (1964). Investigation of inoculant effect on cast iron, Masters Theses, University of Missouri, Rolla, Missouri, 3,6-12

Diego, R. M., Joao, R. S. M. and André de A.V. (2015). Effects of different inoculants on the microstructural characteristics of gray cast iron gg- 25,hardness and useful life of tools, Acta Scientiarum. Technology, 37(4),355-360

Edalati, K., Akhlaghi, F., Nili-Ahmadabadi, M. (2004). Influence of inoculant and/or $\mathrm{SiC}$ addition on characteristics of grey cast iron, International Journal of Cast Metals Research, 17 (3), 147-151, Edward, F., Hugo. F. L. Magdalena, K. and Marcin, G.(2015). Role of alloying additions in the solidification kinetics and resultant chilling tendency and chill of cast iron, Metals, 5(1), pp. 256-288

Fraś, E., Górny, M. and López, H.F. (2014). Mechanism of carbon on the transition from graphite to eutectic cementite in cast iron. Metallurg. Mater. Trans. A 4 (45), 5601-5612.

Haji M. M. (2014). On the inoculation and graphite morphologies of cast iron, Doctoral Thesis Stockholm, Sweden ,13-16

Harold, M. G., Paula, P. E. and Ricardo, A. S. (2017). Fading and graphite nucleation sites in grey iron inoculated using silicon carbide, Matéria (Rio J.), 22 (2) http://dx.doi.org/10.1590/s1517707620170002.0152

Kay, G. and Struers A.S. (2006). Metallographic and materialographic specimen preparation, light microscopy, image analysis and hardness testing, ASTM International

Maschke, W. (2013). Inoculation of cast iron, technical paper, Indian Foundry Journal, 59(8),

Oyetunji, O., Kutelu, B.J. and Akinola, A.S. (2013). Effects of welding speeds and power inputs on the hardness property of type 304L austenitic stainless steel heat-affected zone (HAZ), Journal of Metallurgical Engineering (JME), 2(1), 124-129.

Riposan., I., Chisamera, M., Stan, S. and White, D. (2009). Chilling properties of $\mathrm{Ba} / \mathrm{Ca} / \mathrm{Sr}$ inoculated grey cast irons, International Journal of Cast Metals Research, 20 (2), 90-97.

Saliu, O. S; Sheriff, O. S; Bolarinwa, J. K and Hakeem, O. (2020). Chilling tendency of Iron powder treated grey cast iron, Annals of Faculty Engineering Hunedoara, International Journal of Engineering, 12-22

Seidu, S. O. (2009). Inoculants effect on chilling tendency in ductile iron, International $\mathrm{PhD}$ Foundry Conference, Politehnica University of Bucharest, Materials processing and ecometallurgy, Bucharest-Romania.

Shashikantha, N.,Venkatesha, R . and Raju T. N. (2017). Effect of inoculants on grey cast iron, International Research Journal of Engineering and Technology (IRJET), 04( 09), 2395-0072

Sherrif, O. S., .Saliu, O. S., Taiwo. S.A. and Iulian, R. (2019). Chilling effect of iron powder: The microstructure and hardness property of strongly hypereutectic grey cast iron, Annals of Faculty Engineering Hunedoara - International Journal of Engineering, Tome XVII
Soiński, M. S. and Wawrzyniec A. (2010). Initial assessment of effectiveness of some selected inoculants for grey cast iron, Chair of Foundry, Technical University of Częstochowa, av. Armii Krajowej 19, Częstochowa, Poland.

Stan, S., Chisamera. M. and Riposan I. (2009). Solidification pattern of hypoeutectic grey cast iron in wedge test samples, Politehnica University of Bucharest, Romania 